\title{
Solução hipersaturada de sal ou de glicerina a $98 \%$ como conservantes de centros frênicos caninos utilizados na reparação de defeitos musculares em ratos wistar
}

\author{
Over saturated salt or $98 \%$ glycerin as preservation solutions for canine frenic center utilized in the \\ reparations of muscle lesions in wistar rats
}

\author{
Maurício Veloso Brun ${ }^{1}$ Ney Luis Pippi ${ }^{2}$ David Driemeier ${ }^{3}$ Emerson Antônio Contesini ${ }^{3}$ \\ Carlos Afonso de Castro Beck ${ }^{3}$ Olicies da Cunha ${ }^{4}$ Saulo Tadeu Lemos Pinto Filho ${ }^{5}$ \\ Claudio Roehsig ${ }^{6}$ Rafael Stedile $^{7}$ Thiago Félix da Silva $^{8}$
}

\section{RESUMO}

\begin{abstract}
Com os objetivos de testar a solução hipersaturada de sal (na proporção de $1,5 \mathrm{~g}$ de sal comercial para $1 \mathrm{ml}$ de água tridestilada) como conservante de centro frênico canino e de comparar seus resultados com os da solução de glicerina a 98\% utilizada para o mesmo fim, foram realizados implantes dessa membrana em lesões musculares produzidas em 28 ratos Wistar. Previamente às cirurgias, as soluções foram avaliadas quanto à presença de bactérias e fungos, com resultados negativos. Os defeitos foram produzidos em ambos os músculos retos abdominais de cada animal, e posteriormente reparados com centros frênicos conservados. Os ratos foram separados em sete grupos de igual número, sendo sacrificados aos três, cinco, sete, 10, 15, 30 e 60 dias do pós-operatório, o que permitiu as avaliações macro e microscópicas das regiões de implantação. Ao exame macroscópico foi constatado substituição dos implantes por tecido vivo, sem a ocorrência de eliminação dos mesmos. Ao exame microscópico, observouse que as substituições ocorreram com a deposição de tecido conjuntivo fibroso, sendo que ao final do período de observação, já não existam membranas. Não ocorreram diferenças entre as reações teciduais no local de implantação entre os dois tratamentos. Esses resultados demonstram que os meios de conservação estudados apresentam respostas semelhantes na conservação de centro frênico canino, sendo ambos adequados para tal fim.
\end{abstract}

Palavras-chave: conservação tecidual, soluções conservantes, aloimplante.

\section{ABSTRACT}

Aiming to evaluate the over saturated salt solution (1.5g commercially available salt in $1.5 \mathrm{ml}$ of tridestilled water) as tissue conservator of the canine frenic center and to compare its conservator potential with the well-established glycerin $98 \%$ conservator solution, peaces of this tissue were implanted to repair produced muscle lesions in 28 Wistar rats. Previously both solutions had been tested for bacterial and fungal contaminations, both exams with negative results. In each experimental animal, lesions were made in both Rectus abdominis muscles and repaired with the tissue preserved in both solutions. The animals were divided in seven groups and sacrificed in three, five, seven, 10, 15, 30 and 60 days after reparation for histological evaluation of the implanted region. In macroscopic exam the complete substitution of the implants by live tissue was observed, without rejection of the implanted tissue. In the microscopic evaluation we observed that the substitutions were made by fibrous conjunctive tissue deposition. At the end of the evaluation period, the implanted membranes were not present in repaired regions. In both conserved tissues there were not differences in tissue reactions. The over saturated salt, and $98 \%$ glycerin solutions presented similar results in the canine frenic center preservation indicating that both solutions may be utilized to preserve this membrane.

Key words: tissue preservation, storage solutions, alograft.

\section{INTRODUÇÃO}

Durante muitos séculos, a procura do melhor método para conservação de materiais biológicos vem sendo constante, seja pelo crescente uso dos transplantes homólogos e heterólogos em cirurgia restauradora, seja pela suas vantagens sobre os demais (LEITE et al., 1979).

\footnotetext{
${ }^{1}$ Médico Veterinário, Mestre, Doutor. Professor da Faculdade de Agronomia e Medicina Veterinária da Universidade de Passo Fundo (UPF), Campus I, Bairro São José, BR 285, km 171, 99025-000, Passo Fundo, RS. E-mail:mbrun@upf.tche.br. Autor para correspondência. ${ }^{2}$ Médico Veterinário, Mestre, Doutor, Professor do PPG em Medicina Veterinária, Universidade Federal de Santa Maria (UFSM). ${ }^{3}$ Médico Veterinário, Mestre, Doutor, Professor do Faculdade de Medicina Veterinária, UFRGS.

${ }^{4}$ Médico Veterinário Autônomo, Mestre.

${ }^{5}$ Médico Veterinário, Mestre, Professor da Faculdade de Medicina Veterinária, PUC.

${ }^{6}$ Médico Veterinário, Residente da Universidade Estadual de Londrina.

${ }^{7}$ Médico Veterinário, Aluno do PPG em Medicina Veterinária da UFSM.

${ }^{8}$ Médico Veterinário Autônomo.
} 
Os métodos de conservação para os diferentes tecidos animais podem ser classificados em duas grandes categorias: os que mantêm a vitalidade celular e os que não mantêm (LEITE et al., 1979). Neste último grupo, encontra-se a glicerina a $98 \%$, que atualmente é um dos meios mais amplamente utilizados, tanto em casos clínicos quanto em estudos experimentais (DALECK et al., 1992; LAVALLE et al., 1998; COSTANETO et al., 1999; OLIVEIRAet al., 1999; BRUN et al., 2000; CONTESINI et al., 2001; RAISER et al., 2001). Uma das principais características da glicerina é a capacidade de desidratação celular (PIGOSSI, 1964; PIGOSSI, 1967; ALVARENGA, 1977; DALECK et al., 1987; ALVARENGA, 1992) a qual se atribui a sua ação ação anti-séptica (CHIRIFE et al., 1982), atuando contra fungos e bactérias grannegativas e gran-positivas, com exceção para as formas esporuladas (PIGOSSI, 1967). Cabe ressaltar que a desidratação obtida com a glicerina não altera a concentração iônica das células, o que mantém a integridade celular (PIGOSSI, 1964).

Tal meio também reduz a antigenicidade dos tecidos conservados (PIGOSSI, 1964; PIGOSSI, 1967; RAZANI et al., 1990), o que dispensa a necessidade de utilização de fármacos imunosupressores durante os períodos trans e pós-operatórios. Após a implantação, os materiais biológicos mantidos em glicerina atuam como uma estrutura de sustentação temporária e orientam o crescimento do tecido vivo no leito receptor (OLIVEIRA et al., 1999; RAISER et al., 2001).

Na busca de um meio de conservação alternativo que apresentasse características desidratantes, anti-sépticas e anti-imunogênicas semelhantes ou superiores à glicerina, trabalhos foram desenvolvidos testando o mel não processado (AMENDOLA et al., 2000; AMENDOLA, 2001), a solução hipersaturada de açúcar (GONÇALVEZ, 2000; MAZZANTI et al., 2001) e, mais recentemente, a solução hipersaturada de sal (BRUN et al., 2002). Estes últimos autores utilizaram uma diluição de $1,5 \mathrm{~g}$ de sal grosso comercial para cada $1 \mathrm{ml}$ de água tridestilada, na qual mantiveram o pericárdio canino por um período mínimo de 90 dias. O meio de conservação demonstrou ausência de bactérias e fungos nos testes de cultura realizados. O implante conservado foi utilizado na reparação de defeitos musculares de 24 ratos Wistar, sacrificados aos três, cinco, sete, 10,15 e 30 do período pós-operatório. Nos exames macroscópico e microscópico foi demonstrada neovascularização do local reparado, que paulatinamente foi decrescendo. Ao exame microscópico, pode-se constatar a substituição gradativa do implante por tecido conjuntivo fibroso, sem a ocorrência de eliminação do pericárdio ou contaminação. A solução testada demonstrou apresentar propriedades anti-sépticas, além de manter as características estruturais do pericárdio. O implante funcionou como um arcabouço para o crescimento do tecido vivo, sendo completamente reabsorvido.

O presente trabalho teve como objetivos testar a viabilidade da solução hipersaturada de sal como conservante de centro frênico canino, e comparar os resultados da implantação desta membrana quando conservada neste meio ou em glicerina a $98 \%$.

\section{MATERIAL E MÉTODO}

Os centro frênicos foram coletados de dois cães adultos, sadios, de forma não asséptica, sendo lavados em água corrente e armazenados em frascos limpos contendo solução de glicerina a $98 \%$ ou solução hipersaturada de sal, composta de $300 \mathrm{~g}$ de sal grosso comercial ${ }^{a}$ e $200 \mathrm{ml}$ de água tridestilada. Os frascos foram mantidos em temperatura ambiente por um período de 90 dias. Anteriormente às implantações, os líquidos conservantes foram analisados quanto a presença de bacterias e fungos nos meios agar sangue (AS), thioglycollate (TIO), brain heart infusion (BHI), micobiotic e sabouraud chloranphenicol agar.

Foram utilizados 28 ratos Wistar, fêmeas, pesando em média 226,6g (200-288g). Durante o período de experimentação, os animais foram separados em sete grupos de igual número (GI, GII, GIII, GIV, GV, GVI e GVII), e mantidos em gaiolas apropriadas recebendo ração comercial e água $a d$ libitum.

Os procedimentos cirúrgicos foram realizados sob anestesia dissociativa, mantendo-se os animais em decúbito dorsal. Como medicação préanestésica foi utilizado cloridrato de xilazina ${ }^{\mathrm{b}}$ na dose de $5 \mathrm{mg} . \mathrm{kg}^{-1}$, via intramuscular (IM). Na seqüência, os animais receberam cloridrato de cetamina ${ }^{\mathrm{c}}$, via IM, na dose de $50 \mathrm{mg} . \mathrm{kg}^{-1} \mathrm{e}$ ampicilina sódica ${ }^{\mathrm{d}}$, na dose de 20mg. $\mathrm{kg}^{-1}$, via intraperitonial.

Realizou-se uma incisão mediana ventral de $3,5 \mathrm{~cm}$ de comprimento, até a proximidade da linha alba. O tecido subcutâneo foi dissecado com tesoura de Metzenbaum, permitindo a visibilização de ambos músculos retos abdominais. Inicialmente, foi removido um segmento de $1,5 \mathrm{~cm}$ de comprimento pela metade da largura do músculo reto abdominal direito, procurando-se não perfurar o folheto interno e o peritônio. Manobra semelhante foi realizada no músculo reto abdominal esquerdo. A lacuna produzida do lado direito foi reparada com centro frênico 
conservado em solução hipersaturada de sal, enquanto a do lado esquerdo com a membrana conservada em glicerina.

Previamente à implantação, os centro frênicos foram mantidos imersos, em cubas separadas, em solução fisiológica ${ }^{\mathrm{e}}$ por um período mínimo de 15 minutos. Teve-se o cuidado de irrigar abundantemente o tecido conservado em sal a fim de se remover o excesso de soluto.

Uma vez hidratados, os centros frênicos foram suturados aos músculos oblíquos abdominais internos, oblíquos abdominais externos e retos abdominais, em padrão contínuo simples com náilon monofilamentar $6-0$ f . O tecido subcutâneo e a pele foram suturados com o mesmo fio em padrões contínuo simples e isolado simples, respectivamente.

Para se realizar as avaliações macro e microscópicas das regiões implantadas, os animais foram sacrificados com sobredose de tiopental sódico ${ }^{\mathrm{g}}$ aos três, cinco, sete, 10, 15, 30 e 60 dias do período pós-operatório, conforme o grupo (GI aos três dias, GII aos cinco dias, e assim sucessivamente). Na análise microscópica, as áreas do implante foram clivadas e incluídas em parafina. Cortes de aproximadamente $3 \mu$ foram obtidos em micrótomo vertical e corados pela hematoxilina-eosina e Masson, conforme PROPHET et al. (1992). Nessa análise foram considerados o tipo de reação inflamatória presente, a intensidade de reabsorção do implante e a ocorrência ou não de eliminação do implante.

\section{RESULTADOS}

Ambas as soluções conservantes demonstraram a inexistência de bactérias ou fungos, uma vez que não ocorreu crescimento desses agentes nos meios de culturas analisados.

Não ocorreram complicações transoperatórias, sendo as implantações realizadas em tempo médio de 33,6 minutos (28-43 min.). No pós-operatório, foi observada deiscência parcial da sutura de pele em dois animais (GII e GIII), sem que esta alteração se estendesse até a região de implantação.

Em todos os animais, foi possível evidenciar os locais de implantação, tanto pela presença do fio de sutura como pela coloração das membranas. Na avaliação macroscópica realizada aos três dias de pósoperatório (GI), observou-se que a membrana conservada em solução hipersaturada de sal apresentava coloração amarelada, enquanto a mantida em glicerina coloração esbranquiçada. Ao decorrer das avaliações, o centro frênico conservado em glicerina tornou-se mais opaco em relação à outra membrana.
Esta condição foi melhor evidenciada do décimo quinto dia pós-operatório em diante (GV, GVI e GVII). Durante este mesmo período, tornou-se difícil a delimitação entre o tecido do hospedeiro e os implantes, principalmente na região reparada com o tecido conservado em sal (Figura 1). A vascularização local, que nos animais do GI estava bastante evidente, foi gradativamente decrescendo durante a evolução pósoperatória.

Na avaliação microscópica, observou-se, nos animais do GI, a presença de implantes íntegros circundados por reação inflamatória polimorfonuclear multifocal moderada, associada a infiltrado mononuclear difuso com macrófagos. Essa reação estendeu-se a partir dos centros frênicos até as fáscias musculares profundas. No GII, a reação inflamatória mononuclear associou-se à proliferação de fibroblastos circundando as membranas implantadas, com infiltrados nos feixes musculares. Também se constatou a presença de infiltração mononuclear perivascular. A reação observada nos ratos do GIII não variou de intensidade em relação ao grupo anterior, sendo evidenciada diminuição do tamanho dos implantes, associada a infiltrado mononuclear de fibroblastos e presença de fibrócitos com secreção de colágeno. No décimo dia pós-operatório (GIV), havia proliferação acentuada de tecido conjuntivo fibroso circundando pequenas áreas das membranas implantadas remanescentes, que se estendia ao tecido adjacente. No GV, ainda se evidenciava restos das membranas implantadas, mas a fibrose estava menos acentuada em comparação ao grupo anterior. Em três animais, já não existiam implantes, apenas tecido fibroso. Aos 30 dias (GVI) as observações foram semelhantes. Nos ratos do GVII evidenciou-se ausência do implante associada a formação de uma tênue camada de tecido conjuntivo. Durante todos os períodos de observação, não foram constatadas variações nas reações inflamatórias ou na reabsorção do implante entre os dois tratamentos. Evidenciou-se também que os implantes foram absorvidos mais lentamente nos locais onde se formaram pequenas dobras (junto à área de sutura). A figura 2 demonstra alterações microscópicas observadas em diferentes grupos.

\section{DISCUSSÃO}

As amostras coletadas de ambos os conservantes apresentaram resultados negativos quanto à presença de bactérias e fungos, não havendo crescimento destes agentes nos meios analisados ou no tecido dos animais. A ação anti-séptica da glicerina tem sido comprovada em diferentes trabalhos 


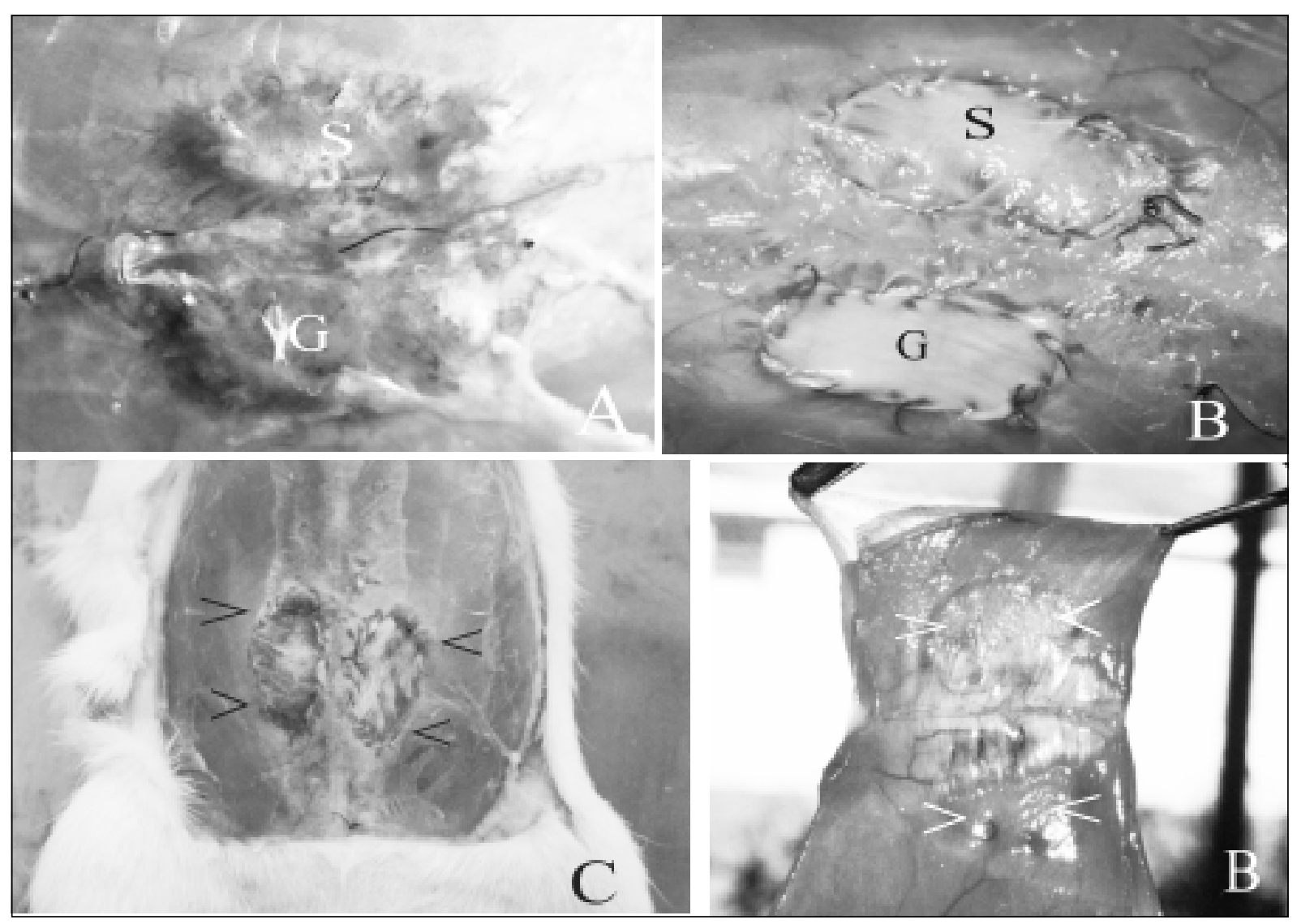

Figura 1 - Avaliações macroscópicas das regiões de implantações de centros frênicos caninos, conservados em solução hipersaturada de sal e glicerina a $98 \%$, em lacunas produzidas nos músculos retos abdominais de ratos Wistar. Em A pode-se observar os locais de implantação das membranas conservadas em sal (S) ou glicerina $(\mathrm{G})$ aos 10 dias do período pós-operatório (GIV). Nessa situação ocorreu vascularização abundante da região. Já em B é possível analisar as membranas aos 15 dias do período pós-operatório. A vascularização apresenta regressão e ambos implantes estão em processo de substituição pelo tecido do animal. Em C (GVI, 30 dias de pós-operatório) em três animais os implantes apresentavam completa substituição por tecido vivo (setas), não sendo observadas diferenças entre os tratamentos. Em D (GVII), pode-se observar os implantes na face interna da musculatura abdominal. Os locais de implantação eram evidenciados pela presença de uma tênue camada de tecido conjuntivo fibroso (setas). Em nenhum dos animais se constatou a presença dos implantes macroscopicamente.

(PIGOSSI, 1964; PIGOSSI, 1967), podendo ser mantida por períodos superiores a 10 anos (BRUN et al., 2000). De forma semelhante ao presente estudo, BRUN et al. (2002) demonstraram que a solução hipersaturada de sal, na proporção de $1,5 \mathrm{~g}$ para $1 \mathrm{ml}$ de água tridestilada, quando utilizada para a conservação de tecidos por período inferior ao supracitado também possui esta ação, provavelmente explicada pela diminuição da atividade de água. Nesse aspecto, a solução de sal analisada pode apresentar vantagens em relação a outros meios alternativos, uma vez que se constatou a presença de bacilos no mel não processado (AMENDOLA, 2001) e que ainda não é possível descartar que a solução hipersaturada de açúcar, na proporção de $3 \mathrm{~g}$ para $1 \mathrm{ml}$ de água tridestilada, destrua completamente os contaminantes bacterianos (MAZZANTI et al., 2001).

O tempo de hidratação de 15 minutos para o tecido conservado em glicerina segue as indicações de SARTORI FILHO et al. (1997). A membrana conservada em sal foi hidratada pelo mesmo período, conforme a constatação prévia de BRUN et al. (2002). Em ambos os casos, os implantes tornaram-se maleáveis e aparentemente mantiveram sua resistência. Devido à comprovada ação antiséptica dos dois meios, observadas em estudos anteriores (PIGOSSI, 1964; PIGOSSI, 1967; DALECK et al., 1987; BRUN et al., 2002) e no presente trabalho, optou-se pela não inclusão de antibióticos 


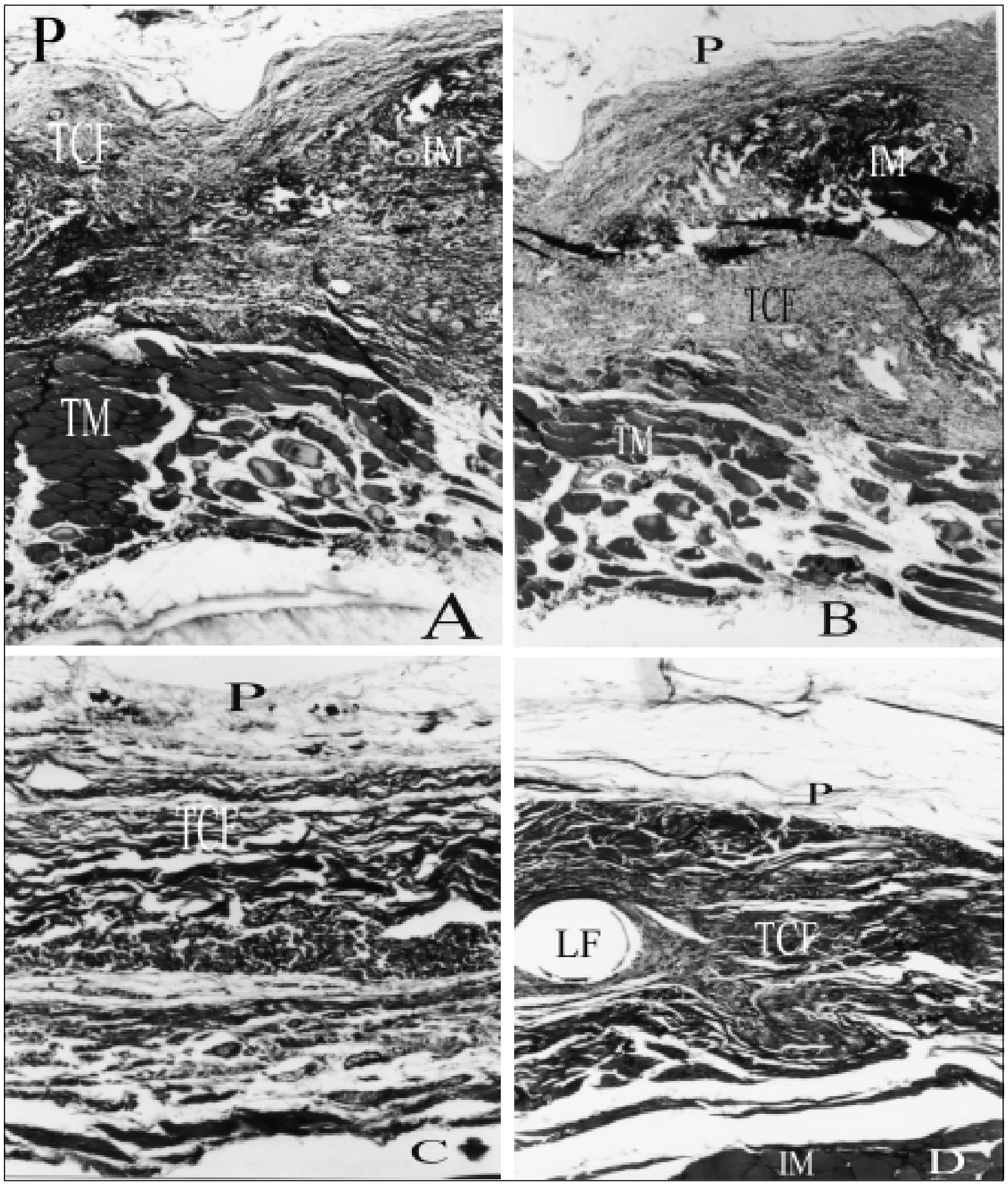

Figura 2 - Avaliações microscópicas das regiões de implantações de centros frênicos caninos, conservados em solução hipersaturada de sal e glicerina a 98\%, em lacunas produzidas nos músculos retos abdominais de ratos Wistar. Nas imagens A e B estão os implantes aos 10 dias do período pós-operatório (GIV). A imagem A corresponde ao local de reparação do defeito com a membrana conservada em sal, enquanto a B está associada ao tecido conservado em glicerina a 98\%. Em ambas situações os implantes (IM) apresentamse infiltrados por tecido conjuntivo fibroso (TCF). Também pode-se observar tecido muscular (TM) e peritônio (P). As imagens C e D correspondem aos locais de implantações das membranas conservadas em sal (C) ou glicerina (D) aos 60 dias do pósoperatório. Em ambas situações os implantes foram completamente substituídos por tecido conjuntivo fibroso. Não se evidenciam diferenças de reação tecidual entre os dois tratamentos. LF corresponde ao local do fio de sutura. 10X.

Ciência Rural, v.34, n.1, jan-fev, 2004. 
na solução hidratante. Conduta semelhante é indicada por GONÇALVES (2000) e MAZZANTI et al. (2001) e demonstra ser apropriada.

Nas observações macroscópicas e microscópicas nos diferentes tempos, evidenciaramse a ausência de eliminação do implante e sua progressiva substituição pelo tecido do tecido do hospedeiro. Este padrão de resposta tem sido constatado após a implantação de materiais biológicos conservados em diferentes meios, como a glicerina (DALECK et al.,1988; RANZANI et al.,1990; COSTANETO et al., 1999; OLIVEIRA et al., 1999; MAZZANTI et al., 2000; RAISER et al., 2001), o mel não processado (AMENDOLA et al., 2000; AMENDOLA, 2001), a solução hipersaturada de açúcar (GONÇALVES, 2000; MAZZANTI et al., 2001), a solução hipersaturada de sal (BRUN et al., 2002), e comprova que o centro frênico canino conservado na solução estudada atua como arcabouço para o desenvolvimento do tecido vivo.

A manutenção do implante nos sete primeiros dias pós-operatórios demonstra a ausência de reação hiperaguda, conforme a declaração de RAZANI et al. (1990). Estes mesmos autores afirmam que a ausência de vasculite leucocitária e linfonuclear no implante argumenta pela não ocorrência de rejeição do tipo humoral e celular, respectivamente. Condições semelhantes foram observadas no presente estudo, em ambas as regiões de implantação. Apesar de não serem realizados testes imunológicos específicos tal como descreve PIGOSSI (1967), estas observações permitem afirmar que a solução hipersaturada de sal na proporção estudada, assim como a glicerina a 98\% (PIGOSSI, 1964; PIGOSSI, 1967; RAZANI et al., 1990), atua diminuindo a antigenicidade do tecido conservado.

Nas avaliações microscópicas, foi demonstrado que o centro frênico mantido em solução hipersaturada de sal foi substituído por tecido conjuntivo fibroso, em velocidade semelhante à observada para o material biológico conservado em glicerina, a partir do décimo quinto dia pós-operatório. Considerando que o sucesso da implantação pode estar diretamente relacionado ao tempo de incorporação do implante, ambas as soluções demonstram serem adequadas para a conservação de centro frênico canino. Em trabalho anterior, BRUN et al., (2002) constataram que o pericárdio mantido em solução salina semelhante havia sido totalmente substituído por tecido conjuntivo fibroso ao final de 30 dias. Já RANZANI et al. (1990) e MAZZANTI et al. (2000) observaram esta mesma condição 60 dias após a implantação pericárdio e segmento muscular conservados em glicerina. Estas variações de tempo entre os autores, incluindo a observada no presente estudo, podem estar relacionadas ao meio de conservação, a preparação prévia dos implantes e a estrutura morfológica dos mesmos (MAZZANTI et al., 2001).

\section{CONCLUSÕES}

Nas condições desse estudo, é possível concluir que a solução hipersaturada de sal, na proporção de $1,5 \mathrm{~g}$ de sal comercial para $1 \mathrm{ml}$ de água tridestilada, apresenta resultados semelhantes à glicerina a $98 \%$ na conservação de centro frênico canino. Ambos os meios são adequados para esse fim, uma vez que apresentam características antisépticas e anti-imunogênicas, e permitem que o implante atue como arcabouço para o tecido de reparação do hospedeiro, quando utilizado na reparação de tecido muscular de ratos Wistar.

\section{FONTES DE AQUISIÇÃO}

a Cisne churrasco, Cabo Frio, RJ.

${ }^{\mathrm{b}}$ Rompum, Bayer, Porto Alegre, RS

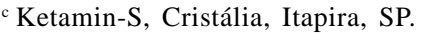

d Ampicilina, Ariston, São Paulo, SP.

e Cloreto de sódio, Texon, Viamão, RS.

${ }^{\mathrm{f}}$ Nylonpoint 6-0, Point Suture do Brasil, Fortaleza, CE.

g Thiopental, Cristália, Itapira, SP.

\section{REFERÊNCIAS BIBLIOGRÁFICAS}

ALVARENGA, J. Possibilidades e limitações da utilização de membranas biológicas preservadas em cirurgia. In: DALECK, C.R. Tópicos em cirurgia de cães e gatos. Jaboticabal: Fundação de estudos e pesquisas em Agronomia - Universidade Estadual Paulista, 1992. p. 33-39.

ALVARENGA, J. Substituição de segmento de colédoco em cães por preparado de pericárdio homólogo conservado em glicerina. 1977. 101f. Tese (Livre Docência) - Curso de Medicina Veterinária, Faculdade de Medicina Veterinária e Zootecnia, Universidade de São Paulo.

AMENDOLA, G.F. Correção de defeito ósseo femural em cães utilizando implante ósseo cortical homólogo conservado em sal. 2001. 46f. Dissertação (Mestrado em Medicina Veterinária, área de concentração em Cirurgia) Programa de Pós-graduação em Medicina Veterinária, Universidade Federal de Santa Maria.

AMENDOLA, G.F. et al. Traqueoplastia em coelhos com centro frênico canino conservado em mel. Ciência Animal Brasileira, v.1 suplemento, p.111, 2000.

BRUN, M.V. et al. Solução hiperstaurada de sal como conservante de pericárdio canino utilizado na reparação do músculo reto abdominal de ratos Wistar. Ciência Rural, v.32, n.6, p.1019-1025, 2002. 
BRUN, M.V. et al. Traqueoplastia em cães com pericárdio eqüino conservado em glicerina por um período de 11 anos. Revista Brasileira de Ciência Veterinária, v.7, suplemento, p.58, 2000.

CHIRIFE, J.; SCARMATO, G.A.; HERSZAGE, L. Scientific basis for use of granulated sugar in treatment of infected wounds. The Lancet, v.1, p.560-561, 1982.

CONTESINI, E.A. et al. Reparação traqueal em cães: transplante autógeno $v s$ implante homógeno conservado em glicerina a $98 \%$ de cartilagem da pina. Ciência Rural, v.31, n.4, p.633-637, 2001

COSTA NETO, J.M. et al. Tenoplastia experimental do calcâneo em cães com peritônio bovino conservado em glicerina. Ciência Rural, v.29, n.4, p.697-703, 1999.

DALECK, C.R. et al. Esofagoplastia cervical em cão com peritônio autólogo ou homólago conservado em glicerina "estudo experimental". Ars Veterinária, v.3, n.2, p.195202, 1987.

DALECK, C.R. et al. Reparação de hérnia perineal em cães com peritônio de bovino conservado em glicerina. Ciência Rural, v.22, n.2, p.179-183, 1992.

DALECK, C.R. et al. Substituição de um retalho diafragmático de cão por peritônio de bovino conservado em glicerina: estudo experimental. Ars Veterinária, v.4, n.1, p.53-61, 1988.

GONÇALVES, G.F. Ceratoplastias lamelar homóloga em cão com conservação em solução supersaturada de açúcar ou glicerina. 2000. 54f. Dissertação (Mestrado em Medicina Veterinária, área de concentração em Cirurgia) Programa de Pós-graduação em Medicina Veterinária, Universidade Federal de Santa Maria.

LAVALlE, G.E.; ARAÚJO, R.B.; PEREIRA, L.C. Uso de pericárdio bovino conservado em glicerina em cão - relato de caso. In: CONGRESSO BRASILEIRO DE CIRURGIA E ANESTESIOLOGIA VETERINÁRIA, 1998, Belo Horizonte, MG. Anais... Belo Horizonte : Colégio Brasileiro de Cirurgia e Anestesiologia Veterinária, 1998. 161p. p.109.
LEITE, J.B.F. et al. A glicerina e a preservação dos tecidos. Revista Paulista de Medicina, v.93, p.81-84, 1979.

MAZZANTI, A. et al. Músculo diafragma homólogo conservado em solução supersaturada de açúcar para a reparação de grande defeito no diafragma de cão. Ciência Rural, v.31, n.2, p.277-283, 2001.

MAZZANTI, A. et al. Reparação da traquéia de cão com segmento muscular homólogo de diafragma conservado em glicerina a 98\%. Ciência Rural, v.30, n.6, p.1011-1016, 2000.

OLIVEIRA, L.O. et al. Implante homógeno de bexiga conservada em glicerina a $98 \%$ para reparo da bexiga de cães. Arquivos da Faculdade de Veterinária UFRGS, v.27, n.1, p.90-102, 1999

PIGOSSI, N. A glicerina na conservação de dura-mater - estudo experimental. 1967. 36f. Tese (Livre docência)

- Faculdade de Medicina de São Paulo, Universidade de São Paulo.

PIGOSSI, N. Implantação de dura-mater homógena conservada em glicerina - estudo experimental em cães. 1964. 41f. Tese (Doutorado em Medicina) - Faculdade de Medicina de São Paulo, Universidade de São Paulo.

PROPHET, E.B. et al. Laboratory methods in histotechnology. Whashington : American Registry of Pathology, 1992. 279p.

RAISER, A.G. et al. Homoimplante ortotópico de tendão calcâneo em cães. Conservação assepsia e implantação. Ciência Rural, v.31, n.1, p.89-94, 2001.

RANZANI, J.J.T. et al. Implante de pericárdio de eqüino preservado em glicerina em solução de continuidade do diafragma de cão. Brazilian Journal Veterinary Research Animal Science, v.27, n.1, p.75-81, 1990.

SARTORI FILHO, R.; GANDOLFI, W.; BANDARRA, E.P. Emprego de membrana biológica (centro frênico) na reparação das lesões tendíneas em coelhos. Veterinária e Zootecnia, v.9, p.69-77, 1997 